\title{
Dynamics of National Supply to the Maquiladora Industry an Approach from the Perspective of the Resource-Based Theory
}

Vargas Hernández JG* and Chávez Torres LCJL

Department of Economics, University Center for Economic and Managerial Sciences, University of Guadalajara, Mexico

\begin{abstract}
The aim of this work is to identify the main obstacles that Mexican companies face in providing goods and services to the maquiladora export industry, and to identify recommendations through the theory of resources and capabilities as well as network theory, in order to help companies to take advantage of its capital and potential strategic alliance. The study method was based on a theoretical and literature review, and studies a case of success. The analysis of results shows in the case of success that an efficient use of resources and the effective establishment of an alliance can improve competitive conditions.
\end{abstract}

Keywords: Maquiladora export industry; Mexican suppliers; Network theory; Theory of resources

\section{Introduction}

With the emergence of the maquiladora industry in the Mexican country during the 60s [1], it was sought as main objective to detonate the Mexican economy as a policy of the Mexican government to increase the number of people employed. This by the benefits that generate foreign direct investment (FDI) in regions where it has decided to establish each company involved and other objectives, among those the increasing local supply to these organizations. According to Solis et al. [2] for 2010 the maquiladora industry in terms of employment it represents approximately 258,000 persons employed and its foreign direct investment was estimated on 1.301 billion.

With the entry into force of the free trade agreements in the early 90 s, there were benefits for maquiladoras such as low tariffs, cheap labor, logistics as the location for the shipment of goods given the proximity with the main market destination (United States) and mainly proximity to sources of supply [3].

The point of the development of local supply is vital for regional economic, since it would increase the share of these in the globalized trade, and translate this into Mexican companies with greater financial capital, fastest growing companies and small and medium industries, development of new technologies, greater employability, etc. Carrillo et al. [3] consider equally the development of local supplier enterprises brings economic growth and stability and to force them to adopt a capacity according to new environments. However they agree that the conditions under which such a firm starts in the market will be in a position of inequality before organizations that already have a way of experience and more resources to meet the demands of their customers.

Although the foreign direct investment is considered as the main engine in the manufacturing industry, mainly from American and Asian organizations [4] this has not represented in Mexico a significant percentage of participation of companies in the nation in their own supply. According to Ollivier [1] by the year 2004 the proportion accounted for about $10 \%$, according to the study of Solis et al. [2] the results showed a rate of $6 \%$, and local investigations only consider participation in a locality was $1.7 \%$ [5]. Actual data that reflect nothing encouraging that one of the main purposes of the program of the maquiladora industry in Mexico has not been met.

This paper analyzes the causes that have provided various authors on the causes or factors that determine this phenomenon in relation to the five business strategies of Peng. Also, in synthesis with networks, capabilities and resources theories and their relationships with the participation of Mexican companies as to the national supply to maquiladoras.

\section{Background of the Problem}

Historically, the maquiladora industry in the Mexican country has represented an important source of jobs and a sector that contributes to regions where industrial dynamics is set to supply networks, job creation, infrastructure of localities and various factors presumed as a spill in technology, knowledge, and among others one of the most important sought, the development of local or national suppliers through the supply of raw materials (goods) or services to large companies transformation.

Faced Mexico with market opening to the free trade agreement emerged an increased in places like Tijuana according to Solis et al. [2], however this hoping growth could be reflected in higher percentages of local suppliers. Today, it cannot be presumed as an achievement resulting from the agreements of this treaty and foreign direct investment that is generated by the establishment of the maquiladoras along the territory. The analysis of this problem has led many researchers to analyze the factors or determinants that caused those local suppliers do not have the desired participation despite the existence of the purpose and intentions of many companies to become part of supply.

Various authors presented factors related to the lack of technology development, previous contracts that companies may have given their conditions of foreign organization, among others.

Dynamic capabilities and capacities impact on sustainable

*Corresponding author: Vargas Hernández JG, Department of Economics, University Center for Economic and Managerial Sciences, University of Guadalajara, Mexico, Tel: +523337703340; E-mail: jvargas2006@gmail.com

Received August 25, 2016; Accepted September 22, 2016; Published September 27, 2016

Citation: Vargas Hernández JG, Chávez Torres LCJL (2016) Dynamics of National Supply to the Maquiladora Industry an Approach from the Perspective of the Resource-Based Theory. J Glob Econ 4: 216. doi: 10.4172/2375-4389.1000216

Copyright: (c) 2016 Vargas Hernández JG, et al. This is an open-access article distributed under the terms of the Creative Commons Attribution License, which permits unrestricted use, distribution, and reproduction in any medium, provided the original author and source are credited. 
competitive advantage [6], it can understand that the theory of resources and capabilities can significantly explain how resources interact with which generally have Mexican companies that are possibly limiting the desired capacity, or possibly develop strategic objective the factors that count and can be used.

The relationship between the resources that could be exploited by Mexican organizations can also be analyzed from the point of view with networks and channels of communication with those who have. There are several forums organized by the government, by various chambers of commerce or defined industry seeking between various objectives the power to create business ties, and improve the exchange of goods and services, but the effectiveness may vary depending on how each company uses for seeking opportunities, or creating a suitable networking. The causes described by various researches, therefore, can be related and focused on how to integrate these challenges into existing company resources and proper management and effective use of them. So, how to generate competitive advantages the creation, development or proper use of networks of contacts that benefits the main purpose of this industrial trade.

\section{Delimitation of the Problem}

Given the stated objectives, they are seeking to attract foreign direct investment through the program of the maquiladora industry, including the growth and participation of local suppliers. However, since the current and historical actual data show that this goal has not been achieved since various factors involving conditions for local businesses and for the maquiladora industry.

At the same time, considering that this degree of complexity described above, it is appropriate to examine whether the existing theory and related to the theory of resources and capabilities as well as the business strategy Peng respective of networks can be a relationship that has a positive impact on the participation of Mexican companies in the supply to the local supply.

Based on the previous analysis, it raises the following research question:

How can exploit current resources and capabilities of enterprises, for generating strategic networks that have a positive impact on local suppliers to the maquiladora industry?

The importance of research focuses on the use of identifying factors that will be proposed based on the causes identified by several authors in the existent literature.

\section{Rationale}

The importance of the maquiladora export industry in Mexico since its inception in 1965, generated an important prognostic investment, and including both economic investment and the spill or better known as spill over in technological aspects, specialization in labor originated a special orientation towards its attraction, particularly during the negotiations and entry into force of the free trade agreements (FTA) with the United States and Canada would create that greater incentives even existed to achieve the purposes. Therefore, given the economic levels and participation of the Maquiladora Export Industry (MEI) in Mexico, it is important to find methods and networks that allow Mexican companies to participate in the distribution chains or supply of these industrial sectors [7].

It is common to find in the various journalistic and economic analyzes sources, that the participation of Mexican companies described is extremely low, and is not meeting the objectives established for the program to promote the maquiladora company, and lack use the free trade agreement. It seems equally that the strategic position of the country has not taken advantage of so that a factor of integration and dependency generated by geography.

There are several programs that the Mexican government promotes for greater integration and generation of strategic networking with potential consumers with these companies that are in availability to meet the demands that could present maquiladora export industries. The purpose of these forums is that large organizations are in local suppliers close allies in those who find benefits as supply and logistics and at the same time positively impact the indicators of local participation in the supply.

It is equally important to analyze the resources and capabilities can be harnessed to generate discussed strategic networks for generating channels of communication or contact as purpose of channeling relations and sales.

\section{Theoretical Assumption}

The efficient use of resources and capabilities of Mexican companies will assist in supplying to the generation of strategic networks and communication channels that can help increase the participation of local suppliers to the maquiladora export industry.

\section{Theoretical Framework Conceptual}

\section{Maquiladora export industry}

According to the National Council of the Maquiladora and Export Manufacturing [8] mean by maquiladora industry as the process of partial manufacturing, assembly and packaging of all products other than the original manufacturer. As detailed a program called promotion of export maquiladora industry (EMI) arises in México during the 1960s with the attraction of these companies with the main purpose of job creation and the economy is looking to strengthen trade balance, promote technological development of the country, etc.

Covering all aspects of the IME, there have been different views on actual contribution to the country, there are different opinions that categorized as a promoter of economic decline in wages, occupational hazards, among other concerns, and on the other positive side there are views that if the maquiladora those goals for which it was founded the program to its attraction [9]. As a historical note by the INDEX, it is considered that the first industrial park installed in the country emerged in 1966 in Ciudad Juarez, Chihuahua. Two years later to 1968, a second park in Nogales, Sonora is installed and starting with these two events an industry that would expand in the coming years mainly in other northern states of Mexico as Tamaulipas, Baja California, etc.

\section{The importance and impact of the maquiladora industry in the national context}

According the INDEX, the IME in the country has gained great importance as it has allowed Mexico to have a technological development, a presence in the global market and constant development for workers who are employed in this sector. According to Alonso et al. [9] with the entry into force of the free trade in North America, disappeared tariffs, the low cost of labor and the proximity of Mexico to markets such as the United States and Canada, attracted the interest towards investing in the development of these activities in the country, generating a strong inflow of foreign exchange. 
Citation: Vargas Hernández JG, Chávez Torres LCJL (2016) Dynamics of National Supply to the Maquiladora Industry an Approach from the Perspective of the Resource-Based Theory. J Glob Econ 4: 216. doi: 10.4172/2375-4389.1000216

Page 3 of 6

According to these authors we can enlist their importance within the following specifications:

Its importance as a source of employment and job creation: According to the INEGI [10] and its monthly survey of the maquiladora industry, the graph in figure 1 below shows historical personnel employed by this sector.

Territorial impact: According to Alonso et al. [9] for 1999 the northern border of Mexico had more than $77 \%$ concentration of maquiladoras, consisting of a national total of 3,243 establishments. For the most current information on INEGI data [10] it is counted a total of 5,006 establishments throughout the republic. They are concentrated mainly in Baja California (17.90\%), Chihuahua (9.60\%), Tamaulipas with (7\%), among others. Today already has seen a significant share of the Interior of the Republic of states like Querétaro (5\%), Jalisco $(5.6 \%)$, etc. (Figure 2$)$.

\section{The national supply and its relationship with the maquiladora export industry}

For purposes of understanding understand the national supply as those producers seeking to position Mexican capital goods and services to the maquiladora and manufacturing for consumption and use in industrial processes industry.

According to Ollivier [1] consumption of the MEI with respect to the supply of goods and services round consumed about 80, 000 billion dollars. However, this consumption does not represent for national supply a higher percentage of participation. By 2004, this percentage remained for $10 \%$ [1], coinciding with the proposal by Solis et al. In previous years, [7], percent between 1990 and 2000 represent between 1.7 and $2.5 \%$

\section{Employed personnel by the MEI}

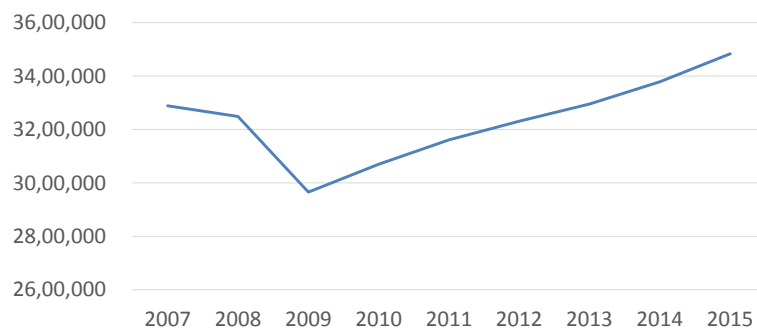

Source: Prepared based on data from INEGI (2016).

Figure 1: Persons employed by the Maquiladora export industry.

\section{Stablishments MEI en México}

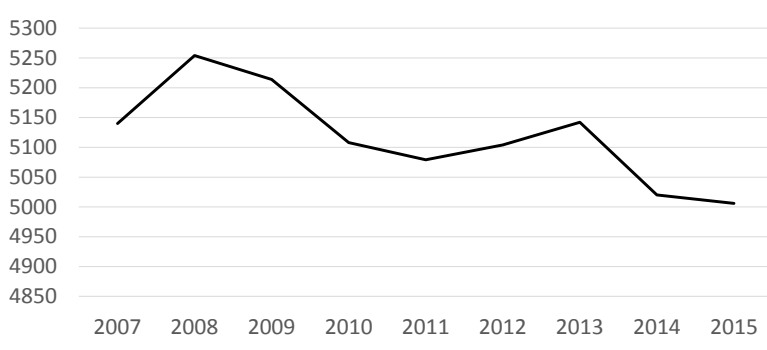

Source: Prepared based on data from INEGI (2016).

Figure 2: Number of establishments in the maquiladora industry in Mexico.
Realizing this literature review, it was found that the percentage of participation that all authors propose is too low and not appreciated being fulfilling one of the goals of fostering maquiladora program, and encourages supply.

\section{Main obstacles of Mexican local supply to the IMMEX}

Through various studies that have been conducted in the country to analyze the different causes or reasons that cause are not generated supply chains or local supply, are analyzed the various factors that the authors propose to have a more global view of be situation. According to [1], who conducted a survey to find the most common causes, obtained the following results as the most common:

- Low tech

- Insufficient volume

- Quality problems

- High prices

- $\quad$ Failure in deliveries

- Certification fouls

Based on the study by Solis et al. [2] found the following grounds:

- Industrial maquiladoras already have contracts with foreign suppliers

- The selection criteria only include transnational suppliers

- Mexican technological capacity limited

- Inability of Mexican local suppliers in terms of volume

- Inability of Mexican local suppliers in terms of on-time delivery

- High and uncompetitive prices

- Lack of certifications and financial strength

Carrillo et al. [3] found in its proposal on the obstacles to linking the Mexican supply similar results to previous studies but adding external factors that are considered important aspects of costs that companies face:

- Mexican technological capacity to meet demand

- High tariffs

- Increase in operating costs

Given the competitive dynamics experienced by Mexican organizations, and based on past research, as a complement is presented the following Table 1 summarizing these causes for further analysis in this trial.

\section{Theory of resources and capabilities}

According to Peng [11], resources are all tangible and intangible assets used by a company to choose and implement their strategies, and capabilities such as the ability to dynamically deploy their resources. Taking into account the main obstacles with which Mexican supply has for a detailed case, it is taken as how this theory can complement the literature and better understand what relationship exists between them.

As examples of resources that have been detailed, Peng [11] exemplifies in the Table 2 below for detail both those intangible or intangible resources. 
Citation: Vargas Hernández JG, Chávez Torres LCJL (2016) Dynamics of National Supply to the Maquiladora Industry an Approach from the Perspective of the Resource-Based Theory. J Glob Econ 4: 216. doi: 10.4172/2375-4389.1000216

If, as proposed, companies with any combination of these factors, occurring as to its use or handling of use according to market needs MEI, which main reasons for their use do not allow them to develop effective strategy. Vargas et al. [6] quoting Collins, disclose that an important point of analysis is the way resources are hoarded, and considering that the accumulation of these is in terms of time can be a lengthy procurement process. Do Mexican companies actually have incentives to generate them, use them and take advantage of them?

If the response is affirmative, Barney [12] details that must perform an analysis of the value chain, and clearly assess whether any of those resources and capabilities contributes significantly to the process of competitive development. The development of some new would have to be an option if not counted, and thereafter will be detailed whether the creation of strategic networks could be one of these options. Given an understanding of the value chain, management should conduct a study known as SWOT (strengths, weaknesses, opportunities and threats) to review how it can be carried out activities against its competitors.

Contextualizing the possible opportunities that a Mexican company may have or not to the supply of the MEI, a synthesis of the framework of Porter's five forces is done, that while it is directed towards the theory based on the industry, it is used to resume to have a more detailed analysis based on various studies to complement this trial, given its already important part of the backbone of the strategic vision. It builds on work on determinants that impede this study of Solis et al. [2] and performing a complete analysis supplemented by several authors mentioned in this paper equally (Table 3 ).

From a point of view to the model VRIO approach (Aspects of value, rarity, ability to imitate and organization of resources); Peng [11] specifies that it is important to analyze these 4 aspects to determine the level of competitive advantage that could have an organization. Taking into account each of the points that this framework assumes, it

\begin{tabular}{|c|c|}
\hline SI.No & Main obstacles of Mexican companies \\
\hline 1 & Limited technology \\
\hline 2 & Inability in fulfillments of time, volume and quality demanded \\
\hline 3 & High price and uncompetitive result of high tariffs and operating costs \\
\hline 4 & Lack of certifications \\
\hline 5 & Selection criteria complicated by the MEI \\
\hline 6 & Contracts or commitments with foreign suppliers MEI \\
\hline
\end{tabular}

Table 1: Main obstacles of Mexican companies.

\begin{tabular}{|c|c|}
\hline Tangibles & Intangibles \\
\hline Financial & Human \\
\hline Physical & Innovation \\
\hline Technology & Reputation \\
\hline
\end{tabular}

Table 2: Tangible and intangible resources. is important to analyze the conditions presented by the national supply articles based on studies in this essay.

Value: As an initial starting in the analysis of competitive advantage, according to the author it can be analyzed only those resources that we provide added value to the business operations that provide an advantage, otherwise those resources that do not do only offer a competitive disadvantage. In what has been discussed with the Mexican grocery, the literature shows that given the inability to fulfill commitments in terms of volume, quality and delivery times. They are negative factors to the pursuit of added value.

Rarity: Given the specific resources which has the organization, it is important to consider that not only are required to have them, if not assess how rare must be or, how are they so different from others on the market that could generate an advantage. Reviewing the literature, it was found that several of the authors detail that Mexican supply has limited technology. It is presumed that the products offered, given this limitation, also do not have remarkable characteristics to what is offered on the market.

Ability to imitate: Considering the above, it can be considered that the same technology factor is limited presumable that the goods do not have characteristics that make them be prone to imitation, or having a difficulty to achieve it.

Organization: As a final aspect of the framework VRIO considers the organization as important point. Although a company has the best products, and notable features, if not come to fulfill a structure that provides effective organization and this in turn will generate development and utilization of its resources, it will be affected.

Reviewing the literature it is found a characteristic for which the Mexican supply fails is lack of certifications and reputation, it is difficult access to productive chains companies MEI (Table 4).

In all, conducting an analysis as described above, and model analysis VRIO, is at a competitive disadvantage and lower average with respect to foreign suppliers and global competition.

\section{Strategic networks}

From an organizational point of view, it must consider alternatives that help Mexican supply to increase the activity it has been developed in this essay, and one of these possible solutions might be developing strategic networks to help achieve this. It must first be understood the meaning of a strategic partnership in order to develop the idea of networks. Peng [11] specifies that alliance agreements are voluntary cooperation between companies. What can be highlighted from this idea? What kind of alliances or networks now these companies can manage to increase their activities? Once it is understood the term alliance, it is important to analyze what is the term strategic network. Following the same line of Peng, the author defines them as: strategic

\begin{tabular}{|c|c|c|}
\hline SI. No & Five forces frame & Observations \\
\hline 1 & Intensity of rivalry among competitors & The MEI has contracts with foreign or place of origin suppliers, generating strong competition \\
\hline 2 & Threat potential inputs & Possible entry of both domestic and foreign suppliers \\
\hline \multirow[t]{3}{*}{3} & \multirow[t]{3}{*}{ Bargaining power of suppliers } & Low technological capacity \\
\hline & & Inability to comply on volumes, time and quality required \\
\hline & & Limited access given the above requirements \\
\hline \multirow[t]{3}{*}{4} & \multirow[t]{3}{*}{ Bargaining power of buyers } & The MEI established as part of supplier selection, transnational corporations \\
\hline & & Certification requirement, door lock to not recognized suppliers \\
\hline & & High demand in time, volume and quality, and keep it constant \\
\hline 5 & Threat of substitutes & Mexican industry does not produce all inputs required, so new suppliers can reduce competitiveness \\
\hline
\end{tabular}

Table 3: Five forces frame in Mexican supply. 
Citation: Vargas Hernández JG, Chávez Torres LCJL (2016) Dynamics of National Supply to the Maquiladora Industry an Approach from the Perspective of the Resource-Based Theory. J Glob Econ 4: 216. doi: 10.4172/2375-4389.1000216

Page 5 of 6

\begin{tabular}{|c|c|c|c|c|c|}
\hline Valuable? & Rare? & $\begin{array}{c}\text { Expensive to imitate } \\
\text { it? }\end{array}$ & $\begin{array}{c}\text { Used by an } \\
\text { organization? }\end{array}$ & Impact on competition? \\
\hline No & -- & -- & No & Competitive disadvantages \\
\hline Yes & No & -- & Yes & Competitive parity \\
\hline Yes & Yes & No & Yes & Temporal competitive advantage \\
\hline Yes & Yes & Yes & Yes & Constant competitive advantage & Superior to average \\
\hline
\end{tabular}

Table 4: Analysis of model VRIO. Is a model or capacity?

networks are strategic alliances formed by multiple companies to compete against similar groups and traditional companies.

For this study also it is understand the term called networking as creating communication channels that give the company possibility of sales or development of communication for its goals. Network theory allows analyzing the myriad of social relations it can be found from the market, linking family and friends, or any form of organization, as detailed by Vera-Cruz et al. [13].

These networks must facilitate a communication channel then to understand formal and informal institutions, government agencies, target customers who are maquiladoras, other suppliers companies in certain period of time that would be competition but could emerge as those organizations with which there are so-called voluntary agreements. Taking into account the contribution made by Vera-Cruz et al. [13] say that they can find 3 types of networks in knowledge networks:

Practice networks: Those where members have daily practices and exchange experiences and knowledge.

Network of interest: Members have similar interests and hobbies and achieve a common enthusiasm for the development of an activity that achieves an attractive increase of profits.

Networking task: Developed for more specialized problems and people that compose be specialists in various areas.

The study of these authors developed a successful case in which an association of companies in Ciudad Juarez, managed to generate a conglomeration of small industries that could meet the demands of the industry, in the case of machine shops. Historically, they say that these workshops emerge as small businesses, where a master turner was the person who had all the knowledge available, however, their activity was not to go out and find customers, on the contrary that these reach them.

Given the initial lack of expertise and tools in the industry, it seeks to train employees that quickly establish their small workshops that maquiladoras hire given its experience, and because these companies are very small, this study highlights that arise the same problems or barriers that were mentioned above: Do not have technological capacity and meet volume, time, quality, or the aspects of certifications such as ISO 9000. However, many maquiladoras ignored these issues being a sector from the point of VRIO view frame, enters the rarity and value. However, in the modern world certifications and technological capabilities given the advances are no longer exclusive matter of a few, but it is the obligation and not counts them out of the market.

\section{The networks of agents in response to the problems they face, and their advantages}

In the case study of Vera-Cruz et al. [13] note that these workshops at the beginning of the conglomerate were 50 establishments, of which the first alliance which was conducted with 22 members by 1973. Since its development out that for 2001, it had 300 shops in the same industry and 58 which begin registering at CANACINTRA begin formal institutional relationships that give them greater success stories.

The advantages of this particular case that were found:

- Exchange organizational experiences

- Share contracts

- Share machines

- Increase the volume

- Be a training school

Given the success story that has represented this alliance, the authors comment that members have developed aspects a mindset of cooperation, shared contracts or recommended, mutual training, etc. This case shows the example of an organization's success; it has made them realize relationships with 50 potential customers' maquiladoras in the city with companies like Lear Corporation carving, General Electric, etc.

Some other alternatives for the development of these communication channels are industrial fairs and national and international conventions seeking the improved linkages between these actors mentioned, such as the Baja SMEs in Baja California, the Expo MRO in Ciudad Juarez, between other examples. It should be noted that the objectives of these forums is that both suppliers of any goods or services expose what its company or organization is able to offer, and buyers of the maquiladora industry can find possible solutions to who are seeking and in this way increase business interaction of both parties.

\section{Analysis of Results}

Based on the literature reviewed, and details that were obtained as major obstacles to domestic procurement and supply, it lists the most common cases to subsequently generate recommendations that the same authors encourage and further propose a case of success study of partnership workshops.

Main obstacles of national supply before the IME:

- Technology limited

- Inability in fulfillments of time, volume and quality demanded

- High price and uncompetitive result of high tariffs and operating costs

- Lack of certifications

- Selection criteria complicated by the MEI

- Contracts or commitments with foreign suppliers MEI

These problems seem to occur throughout the territory where they are installed the maquiladora companies, as given particles and similar conditions that present similar proposals can be generated equally. 
Citation: Vargas Hernández JG, Chávez Torres LCJL (2016) Dynamics of National Supply to the Maquiladora Industry an Approach from the Perspective of the Resource-Based Theory. J Glob Econ 4: 216. doi: 10.4172/2375-4389.1000216

Page 6 of 6

\section{Conclusion}

Given the importance that it is found in the maquiladora activity throughout the territory where it is installed. It has been found to not have a significant participation of Mexican companies in the supply chains that the same companies may require. As it was mentioned, this goal was embodied since its inception in the building plan the maquiladora industry, without reaching a large percentage since the same were established. It is for that in this trial the following steps are proposed for companies to develop a competitive strategy through the efficient use of resources that count as well as the theory of networks by leveraging an alliance or link with other organizations that are in a similar situation.

Main recommendations of the consulted authors and successful case study to counteract the effects of past obstacles:

- Formation of alliances between suppliers can establish competitive prices, combining inventories, processes, machinery, etc.

- Join an alliance of vendors with which to develop a mature organization that is a candidate to join chambers of commerce, industry, etc., and can obtain certifications to increase the prestige or presence.

- Assistance to forums or events organization for the purpose of developing contacts, potential buyers or organizations with which can generate an alliance.

- Developing practice networks with other organizations that can complement their technological capabilities, which help meet time, quality and volume.

- Development of a catalog in conjunction with other companies, for distribution among potential buyers.

- Search of government support for investment in technology and inputs necessary for operations issues.
In conclusion, it can be observed that although the Mexican supply find great challenges, there are success stories as described that help us understand how you can cope better the great competition which may face, as well as the opinions of various authors, who they found similar situation in various regions of the country, and given the conditions in which these operations are in Mexico, the use of this sector for a better competitive positioning strategy and provide them with greater benefits.

\section{References}

1. Ollivier F, Jo Ó (2007) National suppliers to the maquiladora industry in Mexico. A technological challenge. Northern border 19: 191-217.

2. Solís-Quinteros MM, Vega López A, Flores Ortiz MV (2014) Analysis of factors that prevent local supply its foray into the maquiladora industry in Tijuana electronics sector, Baja California, Mexico. University Act 24: 87-94.

3. Carrillo J, Zárate R (2003) Limitations of Mexican suppliers of electronics against foreigners. El Colegio de Sonora 28: 161-162.

4. Alonso J, Carrillo J, Contreras Ó (2002) Technological learning in the maquiladoras of northern Mexico. Northern Border 14: 43-81.

5. Coronado M (2015) Local supply sinks.

6. Vargas-Hernández GGG, Bojórquez-Gutiérrez B (2014) Strategic management of organizations. Buenos Aires, Elaleph

7. Ponce-Rodríguez R, Jiménez-Castañeda R (2012) Determinants of national proveeduría the maquiladora industry: the case of Ciudad Juarez. Economy, society and territory $12: 729-750$

8. http://www.index.org.mx/

9. Alonso J, Carrillo J, Contreras O (2000) Technological trajectories in Asian and American maquiladoras in Mexico. CEPAL.

10. INEGI (2016) Recuperado de.

11. Peng M (2015) Global Strategy. Cenage Learing, México.

12. Barney JB (2008) Evaluating a firm's internal capabilities. Strategic Managements and competitive advantages. New Jersey: Pearson.

13. Vera-Cruz A, Dutrénit G, Gil JL (2003) Networking as a mechanism for capacity building of Mexican maquila suppliers: the case of the machining industry. Small business: cooperação and local desenvolvimento. Rio de Janeiro: Relume DUMARA. 